\title{
O gênero Coryanthes (Orchidaceae-Stanhopeinae) no estado do Mato Grosso, Brasil
}

The genus Coryanthes (Orchidaceae-Stanhopeinae) from state of Mato Grosso, Brazil

\author{
Mathias Erich Engels ${ }^{1,4}$, Lilien Cristhiane Ferneda Rocha ${ }^{2}$ \& Edlley Max Pessoa ${ }^{3}$
}

\begin{abstract}
Resumo
Devido à existência de lacunas sobre o conhecimento do gênero Coryanthes no Mato Grosso, é apresentado o estudo taxonômico das espécies encontradas no estado, além de comentários taxonômicos, ecológicos e históricos. Registramos a ocorrência de quatro espécies do gênero: C. speciosa redescoberta após 87 anos das expedições de Frederico Carlos Hoehne na área; C. dasilvae e C. macrantha novos registros para a região Centro-Oeste do Brasil e C. wenzeliana descrita recentemente, conhecida até então apenas pelo exemplar tipo. Durante esse estudo também foi constatado que o tipo de C. macrantha foi destruído, sendo um lectótipo designado aqui.

Palavras-chave: Cerrado, Cymbidieae, Epidendroideae, flora, Floresta Amazônica.
\end{abstract}

\begin{abstract}
Due to knowledge gaps on the genus Coryanthes from the state of Mato Grosso, is provided a taxonomic study of the species from the state, including ecological, historical and taxonomic comments. Four species of the genus are treated: $C$. speciosa rediscovered in the state after 87 years of Frederico Carlos Hoehne's expeditions; C. dasilvae and C. macrantha new records to the Central-Western region of Brazil and $C$. wenzeliana recently described species, known only from the type specimen. During this study we also discovered that the type of C. macrantha was destroyed, and a lectotype for this name was designed here.
\end{abstract}

Key words: Cerrado, Cymbidieae, Epidendroideae, flora, Amazon Forest.

\section{Introdução}

Coryanthes Hook. foi descrito por Hooker (1831) baseado em C. maculata Hook., além da transferência de C. speciosa (Hook.) Hook. e C. macrantha (Hook.) Hook., as quais eram previamente consideradas em Gongora Ruiz \& Pavon. De acordo com Whitten et al. (2000) o gênero faz parte da subfamília Epidendroideae Kostel., tribo Cymbidieae Pfitzer, subtribo Stanhopeinae Benth. e é monofilético, tendo Sievekingia Rchb.f. como gênero mais relacionado.

Embora vários gêneros da subtribo tenham flores com labelos complexos, Coryanthes se distingue pela coluna provida de um par de glândulas secretoras de líquido, chamadas pleuridias (Gerlach 2009). O gênero possui flores efêmeras, vistosas e com morfologia bastante peculiar, bem como por serem ervas epífitas associadas a formigueiros, sendo dependentes de vários gêneros de formigas como Azteca, Campanotus e Cramatogaster (Gerlach 2009).

Com distribuição neotropical, do México ao sudeste do Brasil, Coryanthes é constituído por cerca de 60 espécies (Marçal \& Chiron 2013; Govaerts 2015). No Brasil o gênero está representado por 20 espécies (Gerlach 2010; BFG 2015), 90\% delas ocorrendo no domínio amazônico (BFG 2015).

\footnotetext{
${ }^{1}$ Assessoria Técnica Ambiental Ltda., R. Marechal José Bernardino Bormann 821, Batel, 80730-350, Curitiba, PR, Brasil.

${ }^{2}$ Juris Ambientis Consultores S S Ltda., R. Humberto Costa 96, Hugo Lange, 80040-150, Curitiba, PR, Brasil.

${ }^{3}$ Universidade Federal de Pernambuco, Lab. Morfo-Taxonomia Vegetal, Depto. Botânica, CCB, Av. Prof. Moraes Rêgo s/n, 50670-901, Recife, PE, Brazil.

${ }^{4}$ Autor para correspondência: mathiasengels@hotmail.com
} 
O gênero Coryanthes é tradicionalmente organizado em duas seções: $C$. sect. Coryanthes, onde o mesoquílo é inteiro e não ornamentado com calos lamelares transversos; e $C$. sect. Lamellunguis Schltr., onde o mesoquílo é dotado de calos lamelares transversos (Schlechter 1916). Porém, essa classificação não tem suporte molecular (Gerlach \& Whitten 2009).

A identificação em nível específico é morosa, tanto devido à similaridade morfológica entre as espécies, bem como pelas flores carnosas e rijas que se deformam durante o processo de herborização.

Apesar de Coryanthes não ser citado para o estado do Mato Grosso por importantes obras, como Flora brasiliensis (Cogniaux 1898), Orchidaceae Brasilienses (Pabst \& Dungs 1975, 1977), Prodromus Florae Matogrossensis (Dubs 1998), Orquideas nativas de Mato Grosso (Koch $\&$ Silva 2012) e pelo The Brazil Flora Group (BFG 2015), o gênero já havia sido registrado para o estado no início do século XX por Hoehne (1910).

Mesmo com espécies possuindo geralmente flores grandes e vistosas, Coryanthes é pouco representado nas coleções biológicas. Isto pode ser explicado em parte pela dificuldade em encontrar espécimes na natureza, graças à floração efêmera, bem como pela dificuldade na coleta e cultivo (devido à relação mutualística com formigas). $\mathrm{O}$ estado do Mato Grosso em especial sofreu por uma grande defasagem na coleta de material botânico para o colecionamento cientifico, bem como pela expressiva diminuição da cobertura vegetal original, fatos estes que ajudam a esclarecer a falta de registros do gênero Coryanthes neste estado (Sasaki et al. 2010; Zappi et al. 2011; Koch \& Silva 2012; Petini-Benelli 2012).

Este estudo tem como objetivo apresentar o tratamento taxonômico das espécies de Coryanthes para o estado do Mato Grosso, incluindo descrições, chave de identificação, comentários taxonômicos e ecológicos, além de pranchas fotográficas das espécies tratadas.

\section{Material e Métodos}

Para o estudo de Coryanthes no estado de Mato Grosso, foi consultado o banco de dados Specieslink (2015), e os herbários CNMT, HB, HERBAM, K, R, RB, SP, TANG, e UFMT [acrônimos dos herbários de acordo com Thiers (continuamente atualizado), exceto Herbário da Universidade Estadual do Mato Grosso - Campus Tangará da Serra (TANG), ainda não indexado no Index Herbariorum]. Além do material previamente coletado no estado, também foram examinados materiais frescos oriundos do resgate de Flora da Usina Hidrelétrica Colíder, os quais foram herborizados segundo as técnicas usuais da taxonomia vegetal (Fidalgo \& Bononi 1989) e depositadas nos herbários CNMT, HERBAM, MBM, TANG e RB.

A terminologia morfológica está de acordo com Gonçalves \& Lorenzi (2011). Os nomes válidos e sinônimos foram adotados de acordo com BFG (2015) e Govaerts (2015). Os dados morfológicos, métricos e de coloração foram aferidos com o material ainda fresco e as descrições foram baseadas no material examinado. As obras originais das espécies encontradas foram consultadas para correta identificação.

\section{Resultados e Discussão}

São apresentadas quatro espécies de Coryanthes para o estado de Mato Grosso: $C$. speciosa recoletada após 87 anos das expedições de Frederico Carlos Hoehne no estado, representando uma redescoberta da espécie na área; $C$. dasilvae F. Barros e C. macrantha (Hook.) Hook., novos registros para a Região Centro-Oeste do Brasil, anteriormente citadas apenas para a Região Norte; e $C$. wenzeliana G.Gerlach \& J.B.F.Silva, espécie recentemente descrita e conhecida até então apenas pelo material tipo.

Coryanthes Hook. Bot. Mag. 58: t.3102. 1831. Espécie tipo: Coryanthes maculata Hook.

Erva cespitosa, epífita, associada a formigueiro. Raízes cilíndricas, alvas. Rizoma cilíndrico, castanho. Pseudobulbos heteroblásticos, estreito-lanceoloides a ovoides, cilíndricos, sulcados, verdes com extremidade apical castanha. Folhas 2-3, apicais, oblanceoladas ou elípticas, cartáceas, planas, base aguda, margem inteira a levemente sinuada, ápice agudo, verdes a discolores, nervuras impressas na face adaxial e salientes na abaxial. Inflorescência racemo simples, axilar basal, ascendente, patente ou pendente, 1-4-flora; pedúnculo curto a longo, cilíndrico, verde ou castanho-esverdeado; brácteas do pedúnculo amplectivas, ovadas ou oblongas, obtusas; raque cilíndrica ou subcilíndrica, verde ou castanho-esverdeada; brácteas florais livres, lanceoladas, ovadas, base aguda, margem inteira, ápice obtuso. Flor ressupinada; ovário + pedicelo cilíndrico, sulcado na soldadura dos carpelos, verde ou verde-acastanhado; sépala dorsal largo- 
ovada, base aguda, arredondada ou subcordada, margem inteira e enrolando-se sobre si mesma, ápice obtuso ou obtuso-apiculado, esverdeado, amarelo ou bege, com ou sem pintas, pintas castanhas a castanho-avermelhadas; sépalas laterais lanceolado-falciformes, base aguda, margem inteira e enrolando-se sobre si mesma, ápice agudo, esverdeado, amarelo ou bege, com ou sem pintas, pintas castanhas a castanhoavermelhadas; pétalas oblongo-falciformes, base aguda, margem sinuada, ápice agudo a obtuso, alvo-esverdeada, amarelo ou bege, com ou sem pintas, pintas castanhas a castanho-avermelhadas; labelo carnoso, rijo, subdividido; hipoquílo arqueado-ascendente ou patente, unguiculado; unguículo hemiesférico ou laminar, arredondado, cônico ou lamelar-bicaloso, com ápice piloso, piloso em ambas a faces ou externamente pilosas e internamente velutina, com coloração variada; mesoquílo descendente, subtubular, glabro, velutino na base ou com faixa dorsal pilosa, com calos lamelares transversos ou com calo na base e interno ao unguículo, com coloração variada; calos lamelares inteiros a bilobados; calo basal inteiro a bilobado, elíptico, arredondado ou ovado, alaranjado, com pintas vináceas a vináceoavermelhadas; epiquílo hemiesférico, calceolar, com calo no centro do terço apical, margem inteira, ápice 3-furcado, com coloração variada; calo subquadrado-sublunar; apículos laterais agudos ou deltoides, incurvados; apículo central espatulado ou subquadrado. Coluna claviforme, levemente achatada dorso-ventralmente, ápice encurvado, com par de glândulas na base (pleuridias), com par de calos na margem da curvatura ventral, com par de alas apicais, verde claro ou alvo, com ou sem pintas castanho-avermelhadas no ventre; glândulas elípticas, elíptico-oblongas ou subdeltoides, achatadas lateralmente, amarelo-alvacentas ou alvas; calos laterais alados, arredondados ou obovais, alvos, alvo-esverdeados ou translúcidos; alas agudas ou deltoides, justapostas à antera, translúcidas ou alvas; antera globosa a subglobosa, alva; polínias 2, elípticas, achatadas dorsoventralmente, sulcadas, cartilaginosas, amarelas; estipe estreito triangular ou deltoide, laminar, alvo; viscidio redondo ou arredondado, alvo. Fruto cápsula deiscente, não totalmente seco na deiscência, seco pós-deiscência, 3-locular, elíptico. Sementes estreitamente elípticas, afiladas, alvas.

\section{Chave para identificação das espécies de Coryanthes do estado de Mato Grosso}

1. Mesoquílo com um calo na base, sem calos lamelares transversos, com faixa dorsal velutina 3. Coryanthes speciosa

1'. Mesoquílo com calos lamelares transversos dispersos, glabro ou velutino, quando velutino, apenas na base.

2. Unguículo do hipoquílo laminar, lamelado-bicaloso

4. Coryanthes wenzeliana

2'. Unguículo do hipoquílo hemiesférico, arredondado.

3. Pedúnculo da inflorescência $>9 \mathrm{~cm}$ compr.; flores inteiramente amarelas; mesoquílo glabro 1. Coryanthes dasilvae

3'. Pedúnculo da inflorescência com até $9 \mathrm{~cm}$ compr.; flores bege com pintas castanhoavermelhadas; mesoquílo velutino na base. 2. Coryanthes macrantha

Coryanthes dasilvae F.Barros, Hoehnea 28: 280 (2001). Tipo: BRASIL. AMAZONAS: Coari, Projeto Urucu, cultivado no Instituto de Botânica, 26.XI.1989, fl., J.B.F. da Silva $s / n$ [holótipo: SP349493 (foto!)]. $\quad$ Fig. 1

Raízes ca. $2 \mathrm{~mm}$ diâm. Rizoma ca. $5 \mathrm{~mm}$ diâm., ca. $1 \mathrm{~cm}$ compr. entre pseudobulbos. Pseudobulbos 4-4,6 × 1,8-2,4 cm, lanceoloideovoides. Folhas 2, 26,5-31,2 × 4,9-8,3 cm, oblanceoladas. Inflorescência patente se tornando pendente, 2-flora; pedúnculo ca. $31 \times 0,3-0,4 \mathrm{~cm}$, verde; brácteas do pedúnculo $1-1,9 \times$ ca. $1 \mathrm{~cm}$, oblongas; raque ca. 1,7 $\times 0,3 \mathrm{~cm}$, cilíndrica, verde; brácteas florais ca. 2,6 $\times 1 \mathrm{~cm}$, lanceoladas. Flor com ovário + pedicelo 6-6,3 $\times$ ca. $0,5 \mathrm{~cm}$, verde; sépala dorsal ca. $2,2 \times 2 \mathrm{~cm}$, amarelo-claro; sépalas laterais ca. 4,5 × 3,5 cm, amarelas; pétalas ca. $3,4 \times 0,6 \mathrm{~cm}$ amarelo-claras; labelo subdividido; hipoquílo ca. 2,6 × 2,3 cm, patente; unguículo hemiesférico, arredondado, sem reentrância no dorso, centro-apical velutino em ambas a faces, amarelo; mesoquílo ca. $2 \times 1,6 \mathrm{~cm}$, glabro, com 


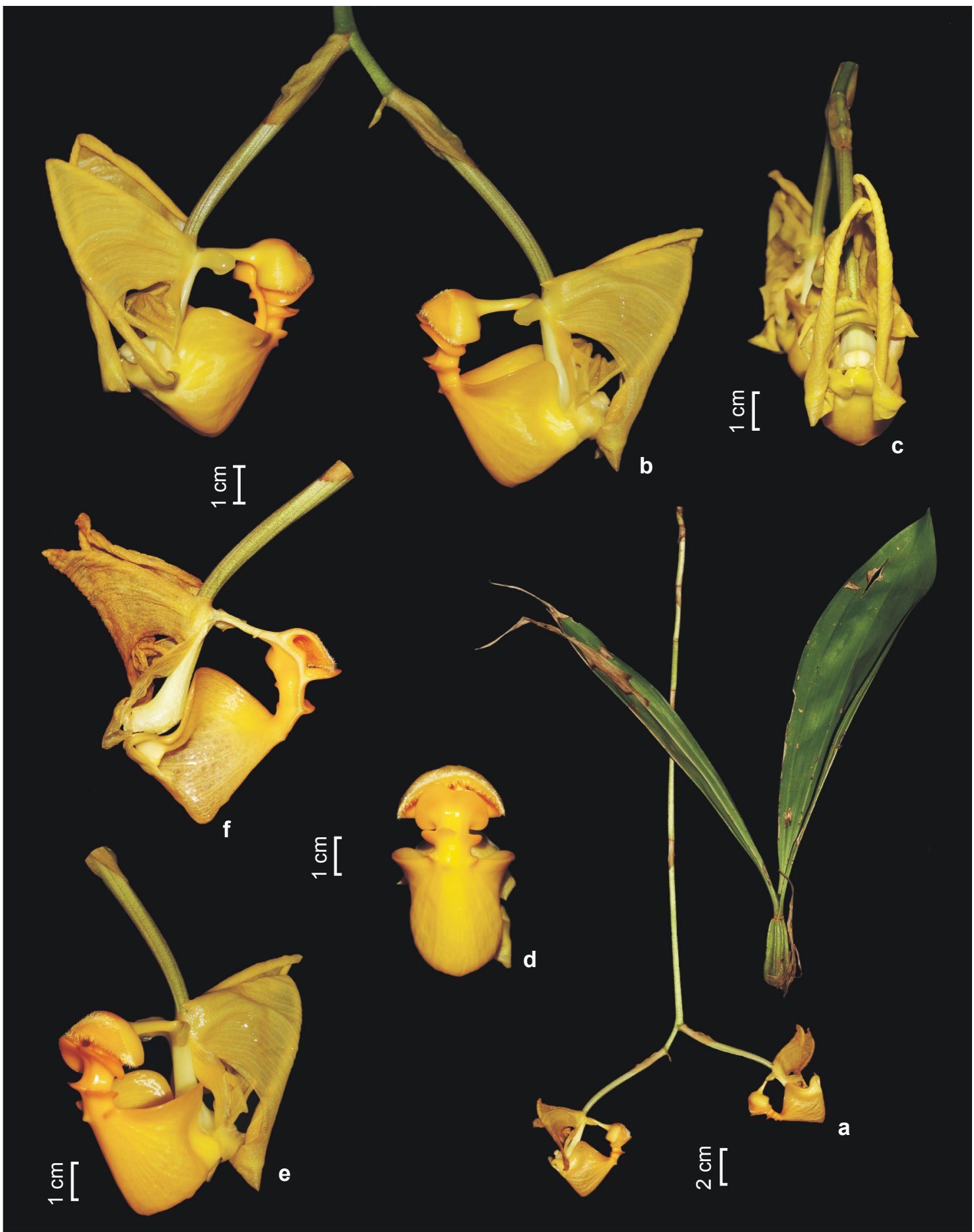

Figura 1 - Coryanthes dasilvae F.Barros - a. Inflorescência, pseudobulbo e folhas; b. detalhe da inflorescência; c-f. flor; c. vista frontal; d. vista dorsal; e. vista dorsolateral; f. vista lateral com labelo seccionado.

Figure 1 - Coryanthes dasilvae F.Barros - a. inflorescence, pseudobulb and leaf; b. detail of the inflorescence; c-f. flower; c. frontal view; d. dorsal view; e. dorso-lateral view; f. lateral view with sectioned lip. 
calos lamelares transversos, maior na base, amarelo escuro; calos lamelares 0,2-1,2 × 0,1-1,6 cm, inteiros a bilobados, amarelo-escuro; calo basal ausente; epiquílo ca 2,6 × 5,6 cm, amarelo; calo ca. $1 \times 2 \mathrm{~mm}$; apículos laterais ca. $7 \times 4 \mathrm{~mm}$, agudos; apículo central ca. $1,1 \times 0,7 \mathrm{~cm}$, espatulado. Coluna ca. $3 \times 1,5 \mathrm{~cm}$, verde claro; glândulas ca. $7 \times 3 \mathrm{~mm}$, elípticas, amarelo-alvacentas; calos laterais ca. $4 \times 3 \mathrm{~mm}$, arredondados, translúcidos; alas ca. $4 \times 3 \mathrm{~mm}$, agudas, translúcidas; antera ca. $4 \times 4 \mathrm{~mm}$, globosa, alva; polínias ca. $2 \times 1 \mathrm{~mm}$; estipe ca. $2 \times 1 \mathrm{~mm}$, estreito triangular; viscidio ca. $1 \times 1,5 \mathrm{~mm}$, arredondado. Fruto e sementes não vistos.

Material examinado: Itaúba, Resgate de Flora da UHE Colíder, lote C de supressão, 8.XII.2014, fl., M.E.Engels \& R.Barreto 3317 (MBM); Juina, linha de transmissão HE-Juina, 9.IX.2009, fl., A.Petini-Benelli 34LTJU (UFMT).

Coryanthes dasilvae é endêmica do Brasil e conhecida até então apenas para localidade típica no estado do Amazonas (BFG 2015; Govaerts 2015). Este novo registro amplia sua área de distribuição para a Região Centro-Oeste do Brasil.

O espécime oriundo do rio Teles Pires foi coletado como epífita sobre formigueiro em árvores do estrato médio da floresta, a aproximadamente oito metros. Esta espécie foi encontrada florida em novembro e dezembro com flores durando cerca de quatro dias. A coloração das flores varia do amarelo mais claro na antese para amarelo mais escuro na senescência. A inflorescência do material examinado é pendente, divergindo do observado por Barros (2001), onde o pedúnculo era ereto a subereto.

Coryanthes dasilvae foi descrita para o estado do Amazonas, sendo comparada na obra original a C. toulemondiana G.Gerlach \& T.Franke e C. gerlachiana Senghas \& Seeger, as quais se assemelham especialmente pelas flores completamente amarelas, além de forma e indumento do hipoquílo. De acordo com Barros (2001), pode ser diferenciada de C. toulemondiana pela inflorescência ereta a subereta, flores menores, hipoquílo externamente velutino e óstio do epiquílo mais fechado, e de C. gerlachiana pela inflorescência ereta a subereta, pelos formatos distintos do epiquílo e mesoquílo e pelas lamelas transversas do mesoquílo mais curtas. No Brasil, outra espécie no gênero possui flores amarelas sem pintas é $C$. elianae M.F. Silva \& A.T. Oliveira, porém esta possui mesoquílo sem lamelas. Coryanthes dasilvae pode ser diferenciada das demais espécies de Mato Grosso pelas flores amarelas sem pintas, mesoquilo com calos lamelares transversos e pelo hipoquílo hemiesférico velutino.

Coryanthes macrantha (Hook.) Hook., Bot. Mag. 58: t. 3102.1831.

Gongora macranta Hook., Bot. Misc. 2: 151, t. 80. 1831. Tipo: VENEZUELA. CARACAS: cultivado em Trindade, X.1829, fl. D. Lockhart $s / n$ [holótipo: $\mathrm{K}$ (flor em álcool), destruída fide curadoria do herbário $\mathrm{K}$ (com. pess.), lectótipo: Hooker W.J., Botanical Miscellany 2: tabula LXXX (1831), ilustração original nos arquivos do Jardim Botânico Real de Kew, aqui designado].

Figs. 2,3

Raízes ca. 0,2 cm diâm. Rizoma ca. $1 \mathrm{~cm}$ diâm., ca. 2 cm compr. entre pseudobulbos. Pseudobulbos 7,5-13,2 × 1,8-3 cm, lanceoloides. Folhas 2, 63-69,5 × 8,5-9,3 cm, oblanceoladas. Inflorescência pendente, 2-flora; pedúnculo $6,2-9 \times 0,5-0,7 \mathrm{~cm}$, castanho esverdeado; brácteas do pedúnculo $1,2-1,7 \times 1,6-2,1 \mathrm{~cm}$, ovadas; raque $0,8-1 \times 1,1-1,3 \mathrm{~cm}$, cilíndrica, castanho esverdeada; brácteas florais 4,4-4,6 × 3,7-4,4 $\mathrm{cm}$, ovadas. Flor com ovário + pedicelo 7,5-10 $\times 0,6-0,7 \mathrm{~cm}$, verde-acastanhado; sépala dorsal 4,5-5 × 3,5-4 cm, bege, com pintas castanhoavermelhado; sépalas laterais 8,2-9 ×6,5-7,7 cm, bege, com pintas castanho-avermelhado; pétalas 5-6 × 1,2-1,3 cm, bege, com pintas castanhoavermelhado; labelo subdividido; hipoquílo 5-5,7 $\times$ 4-4,5 cm, patente; unguículo hemiesférico, arredondado, com ou sem reentrância no dorso, lateralmente piloso e com face interna velutina, acastanhado, com pintas castanho-avermelhadas; mesoquílo 3,5-4,7 × 2,2-2,5 cm, velutino na base, com calos lamelares transversos, maior na base, castanho-avermelhado, escuros; calos lamelares 3-8 × 2-7 mm, inteiros a bilobados, castanho-avermelhados; calo basal ausente; epiquílo 7,6-8,5 × 9,8-10,8 cm, bege, com pintas castanho-avermelhadas, calo ca. $6 \times 8$ $\mathrm{mm}$; apículos laterais $1,1-1,3 \times 1,1-1,3 \mathrm{~cm}$, deltoides; apículo central 1,4-1,5 × 1,2-1,4 cm, subquadrado. Coluna 4,2-4,6 × 2,6-2,7 cm, alvo, com pintas castanho-avermelhadas; glândulas 6-7 × 5-6 mm, subdeltoide, alvas; calos laterais 12-17 × ca. $4 \mathrm{~mm}$, obovais, alvos; alas 7-10 $\times$ ca. $5 \mathrm{~mm}$, deltoides, alvas; antera ca. $7 \times 7 \mathrm{~mm}$, globosa, alva; polínias ca. $4 \times 2 \mathrm{~mm}$; estipe ca. 6 $\times 2 \mathrm{~mm}$, estreito-triangular, alvo; viscidio ca. $3 \times$ $3 \mathrm{~mm}$, arredondado. Fruto e semente não vistos. 


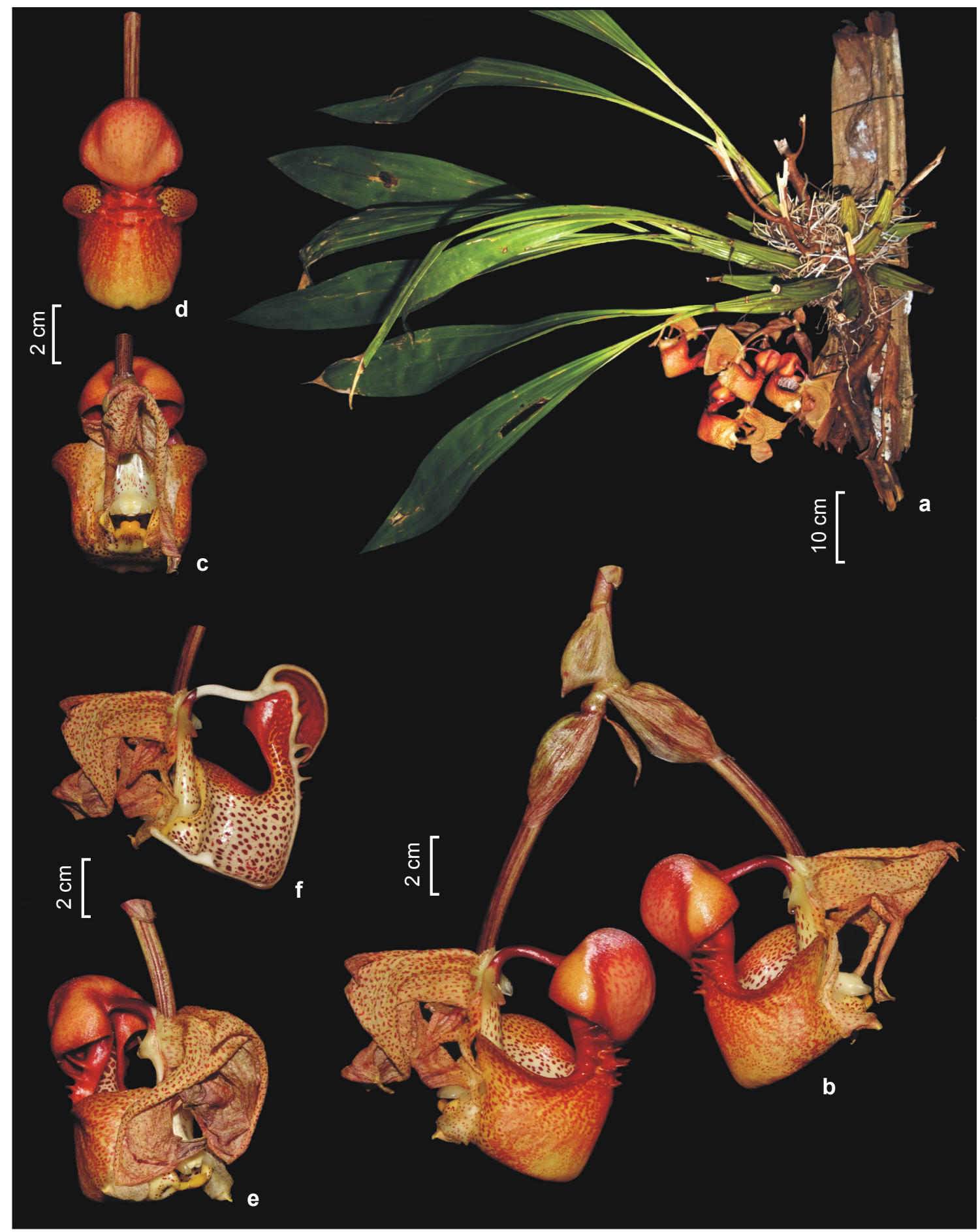

Figura 2 - Coryanthes macrantha (Hook.) Hook. - a. hábito; b. detalhe da inflorescência; c-f. flor; c. vista frontal; d. vista dorsal; e. vista fronto-lateral; f. vista lateral com labelo seccionado.

Figure 2 - Coryanthes macrantha (Hook.) Hook. - a. habit; b. detail of the inflorescence; c-f. flower; c. frontal view; d. dorsal view; e. fronto-lateral view; f. lateral view with sectioned lip. 
Material examinado: Itaúba, Resgate de Flora da UHE Colíder, lote G de supressão, 10.IX.2015, fl., M.E.Engels 3571 (HERBAM, MBM).

Coryanthes macrantha ocorre no Brasil, Colômbia, Guiana, Guiana Francesa, Peru, Suriname, Trindade e Venezuela (Govaerts 2015). No Brasil é encontrada na região Norte, nos estados do Amazonas, Amapá e Pará (BFG 2015), este novo registro para a Região CentroOeste representa o seu limite sul de distribuição geográfica conhecido.

Foi coletada como epífita sobre formigueiro em árvore do estrato médio da floresta. Encontrada florida em setembro, flores durando cerca de cinco dias.

Gongora macrantha Hook. foi descrita a partir de uma flor enviada ao herbário K, em álcool, proveniente da Venezuela e cultivada na ilha de Trindade. O tipo desta espécie foi destruído pelo tempo (Curadoria do herbário $\mathrm{K}$, comunicação pessoal), sendo a ilustração original designada como lectótipo para este nome (Fig. 3). Entre as espécies do Mato Grosso pode ser reconhecida

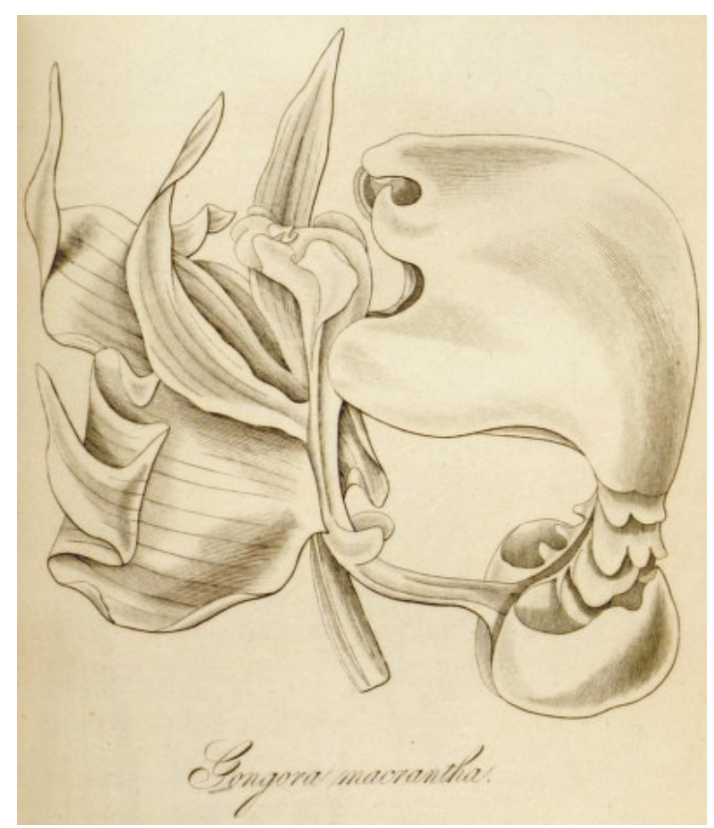

Figura 3 - Coryanthes macrantha (Hook.) Hook. (como Gongora macrantha Hook.). Lectótipo designado aqui: ilustração original, utilizada por Hooker ao descrever a espécie (extraído de Hooker 1831, t.80).

Figure 3 - Coryanthes macrantha (Hook.) Hook. (as Gongora macrantha Hook.). Lectotype here designed: original illustration used by Hooker to describe the species (extracted from Hooker 1831, t.80). pela inflorescência pendente bastante curta (com pedúnculo até $9 \mathrm{~cm}$ compr.); flores grandes (até ca. $12 \mathrm{~cm}$ diâm.), de coloração bege, com pintas castanho-avermelhadas; e pelo mesoquílo do labelo densamente caloso-lamelado.

Coryanthes speciosa (Hook.) Hook., Bot. Mag. 58: t. 3102 (1831).

Gongora speciosa Hook., Bot. Mag 54: t.2755. 1827. Tipo: BRASIL. BAHIA: Sine loco acurato, V.1827, H. Harrison s.n. (holótipo K463392!).

Figs. 4-6

Raízes $0,1-0,3 \mathrm{~cm}$ diâm. Rizoma 5-6 mm diâm., 1-2,2 cm compr. entre pseudobulbos. Pseudobulbos 12,1-16 × 0,8-1,8 cm, estreitolanceoloides a lanceoloides. Folhas 2, 39,1-58,2 $\times$ 3-5,6 cm, oblanceoladas. Inflorescência pendente, 1-4-flora; pedúnculo 30-78,2 × 0,2-0,5 cm, castanho-esverdeado; brácteas do pedúnculo 1,1-2,8 × 0,7-1,8 cm, oblongas, oblanceoladas ou ovadas; raque $3,8-12,4 \times 0,1-0,4 \mathrm{~cm}$, cilíndrica a subcilíndrica, castanho-esverdeada; brácteas florais 2,1-4 × 1,2-2,5 cm, elípticas, lanceoladas ou ovadas. Flor com ovário + pedicelo 5,3-8,5 $\times 0,4-0,5 \mathrm{~cm}$, verde; sépala dorsal 2,6-2,8 $\times$ 4,2-4,4 cm, amarelas, com pintas castanhas a castanho-avermelhadas; sépalas laterais 6,7-10 $\times 3,5-4,8 \mathrm{~cm}$, amarelas, com pintas castanhas a castanho-avermelhadas; pétalas 2,8-5 × 0,5-0,9 cm, amarelo-acastanhadas; labelo subdividido; hipoquílo $2-3,6 \times 1,9-2,3 \mathrm{~cm}$, arqueadoascendente; unguículo hemiesférico, arredondado a cônico, com reentrância no dorso, externamente centro-apical velutino e internamente velutino, externamente amarelo ou alvo, com pintas castanhas ou castanho-vináceas, internamente laranjadas, com pintas vináceas; mesoquílo 2,8-3,7 $\times 1,2-1,5 \mathrm{~cm}$, com faixa dorsal velutina, com calo na base e interno ao unguículo, alvo ou amarelo, com pintas vináceas ou castanhas; calos lamelares transversos ausentes; calo basal 5-10 × 5-8 $\mathrm{mm}$, inteiro a bilobado, elíptico, arredondado ou ovado, alaranjado, com pintas vináceas a vináceoavermelhadas; epiquílo 4-6 × 5,4-8 cm, amarelo, com pintas castanhas a castanho-avermelhadas, calo ca. $5 \times 5 \mathrm{~mm}$; apículos laterais 7-8 $\times 3-4$ $\mathrm{mm}$, agudos; apículo central $1-1,1 \times 0,4-0,5$ $\mathrm{cm}$, espatulado. Coluna 2,5-3 × 1-1,2 cm, verde claro, com pintas arroxeadas no ventre; glândulas 7-10 × 4-5 mm, elíptico-oblongas ou oblongas, amarelo-alvacentas; calos laterais 6-7 $\times$ ca. $3 \mathrm{~mm}$, alados, arredondados, translúcidos; alas 3-4 × 2-3 $\mathrm{mm}$, agudas, translúcidas; antera 5-6 6 ca. $4 \mathrm{~mm}$, 


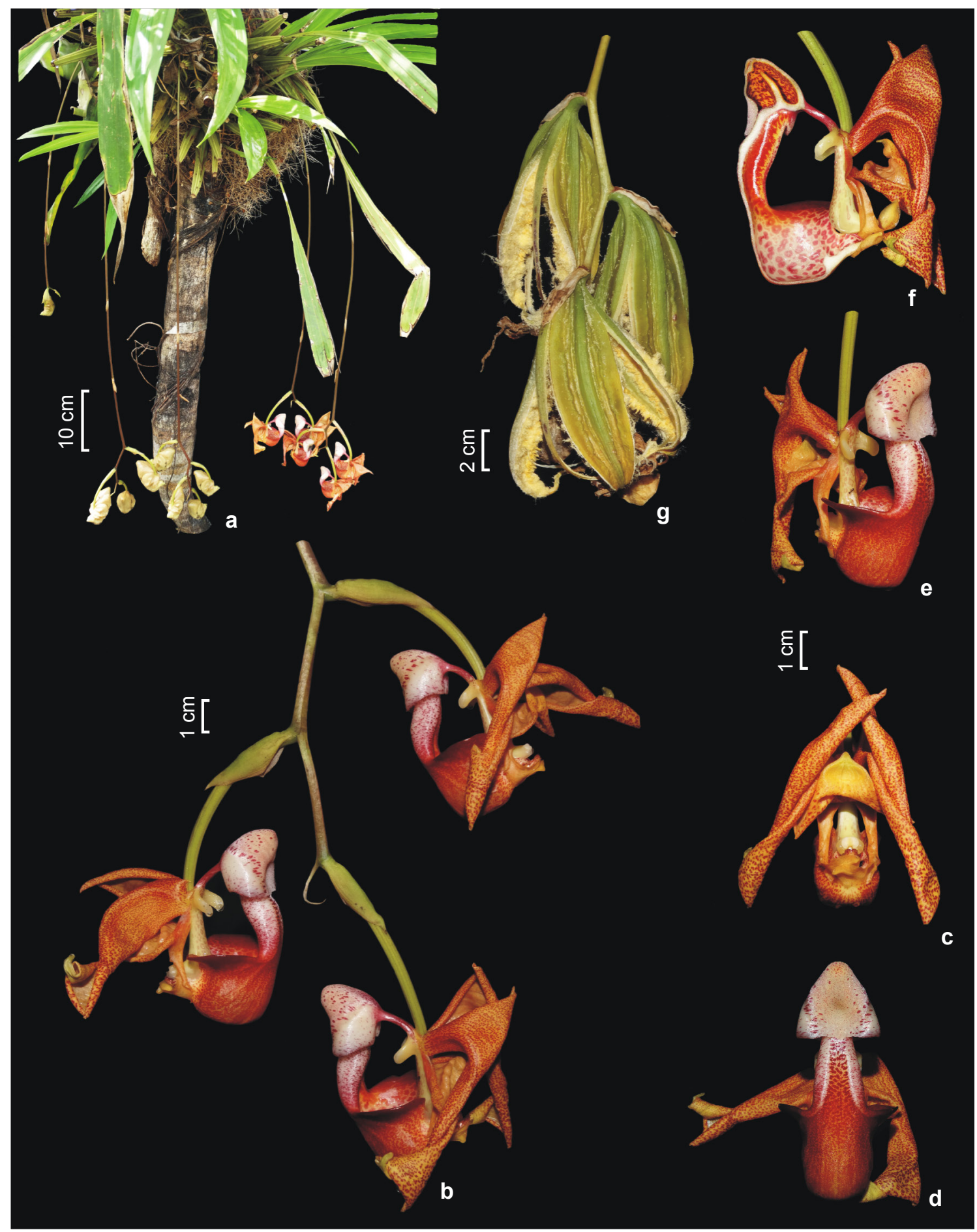

Figura 4 - Coryanthes speciosa (Hook.) Hook. - a. hábito; b. detalhe da inflorescência; c-f. flor; c. vista frontal; d. vista dorsal; e vista dorsolateral; f. vista lateral com labelo seccionado; g. frutos em deiscência.

Figure 4 - Coryanthes speciosa (Hook.) Hook. - a. habit; b. detail of inflorescence; c-f. flower; c. frontal view; d. dorsal view; e. dorsolateral view; f. lateral view with sectioned lip; g. fruits in dehiscence. 
subglobosa, alva; polínias 2 , ca. $3 \times 1 \mathrm{~mm}$; estipe ca. $2 \times 1 \mathrm{~mm}$, estreito-triangular; viscídio ca. $1 \times$ $1-1,5 \mathrm{~mm}$, redondo a arredondado. Fruto maduro 9,5-10 × 4-5 cm, verde. Semente ca. $1 \mathrm{~mm}$ compr., estreitamente elípticas, afiladas, alvas.

Material examinado: Colíder, Resgate de Flora da UHE Colíder, lote B de supressão, fl., 3.XI.2014, M.E.Engels 3324 (MBM); fl., 24.IX.2014, M.E.Engels 3406 (HERBAM, CNMT, MBM, RB, TANG); 30.V.2015, M.E.Engels 3408 (MBM, TANG); 10.VIII.2015, fr. M.E.Engels 3409 (MBM). Itaúba, Resgate de Flora da UHE Colíder, lote C de supressão, fl., 3.X.2014, M.E.Engels \& R.Barreto 3323 (MBM); fl., 23.X.2014, M.E.Engels 3407 (MBM). Juruena, fl., V.1909, F.C.Hoehne 2012 (R). Santa Carmem, margem do rio Arraias, Fazenda Jamanchim, fl., 9.IX.1996, R. Godinho et al. 228 (UFMT).

Coryanthes speciosa ocorre no Brasil, Guiana, Guiana Francesa, Peru, Suriname,
Trindade e Tobago e Venezuela (Govaerts 2015). No Brasil corresponde à espécie do gênero com maior distribuição geográfica, pois de acordo com BFG (2015) pode ser encontrada nos estados do Amazonas, Bahia, Espírito Santo, Pará, Paraíba, Pernambuco, Rio de Janeiro e Roraima. Embora não seja citada a ocorrência desta espécie para o Mato Grosso por BFG (2015), a mesma foi coletada por Frederico Carlos Hoehne durante as expedições da "Commissão de Linhas Telegraphicas Estrategicas de Matto Grosso ao Amazonas" (página 47, tábua $\mathrm{n}^{\circ} 37$ ). Hoehne (1910) tratou o material como C. maculata var. splendens Cogn., já na Flora Brasilica (Hoehne 1942) tratou este mesmo material como $C$. punctata Beer, atualmente ambos os nomes são sinônimos de C. speciosa (BFG 2015; Govaerts 2015). Este material (F.C.Hoehne 2012) oriundo
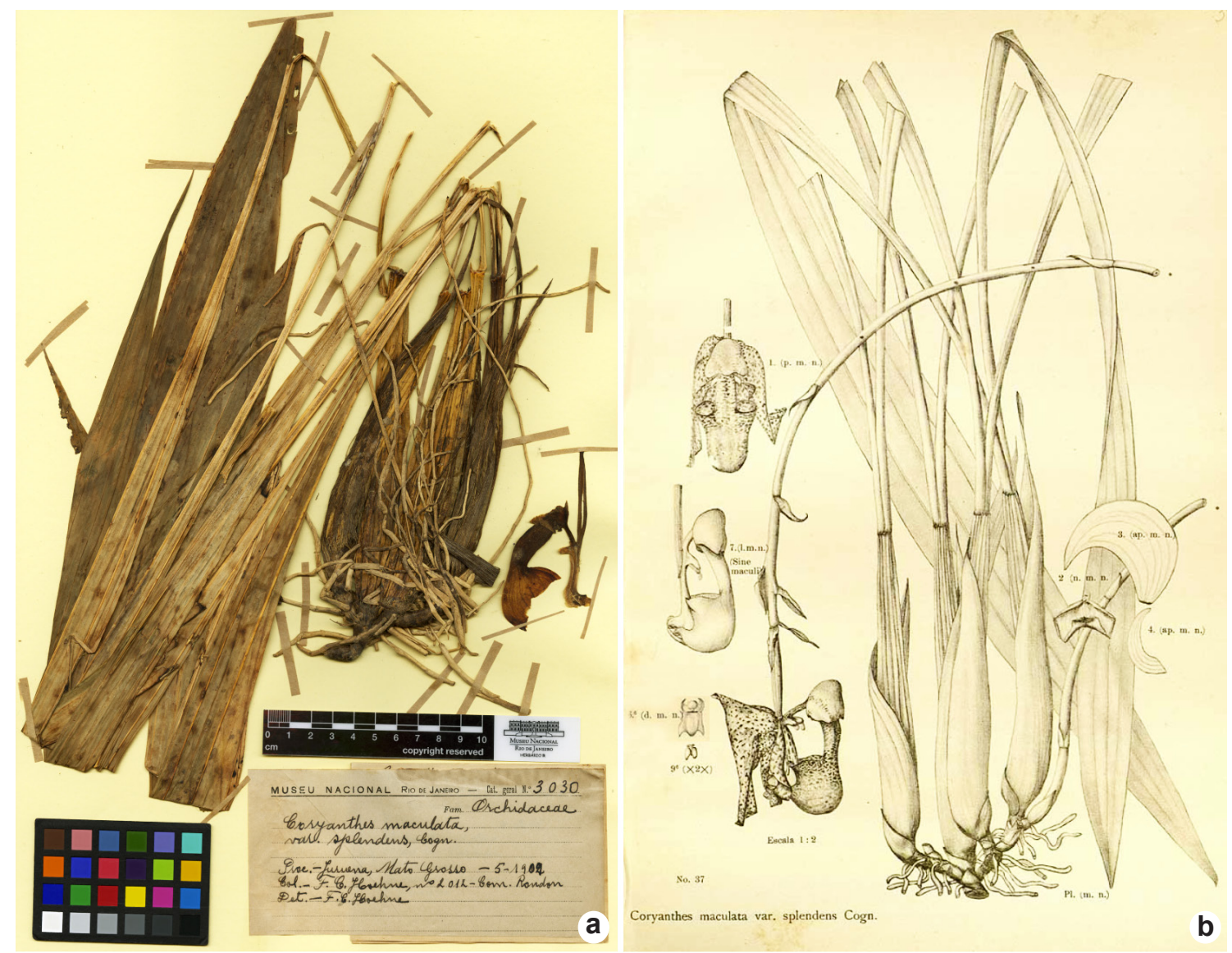

Figura 5 - Coryanthes speciosa (Hook.) Hook. (como Coryanthes maculata var. splendens Cogn.), primeiro registro do gênero Coryanthes Hook. para o estado do Mato Grosso, Brasil - a. exsicata F.C.Hoehne 2012 (R3030); b. ilustração de F.C.Hoehne 2012 (extraído de Hoehne 1910).

Figure 5-Coryanthes speciosa (Hook.) Hook. (as Coryanthes maculata var. splendens Cogn.), first record of genus Coryanthes Hook. in the Mato Grosso State, Brazil - a. voucher F.C.Hoehne 2012 (R3030); b. illustration of F.C.Hoehne 2012 (extracted from Hoehne 1910). 


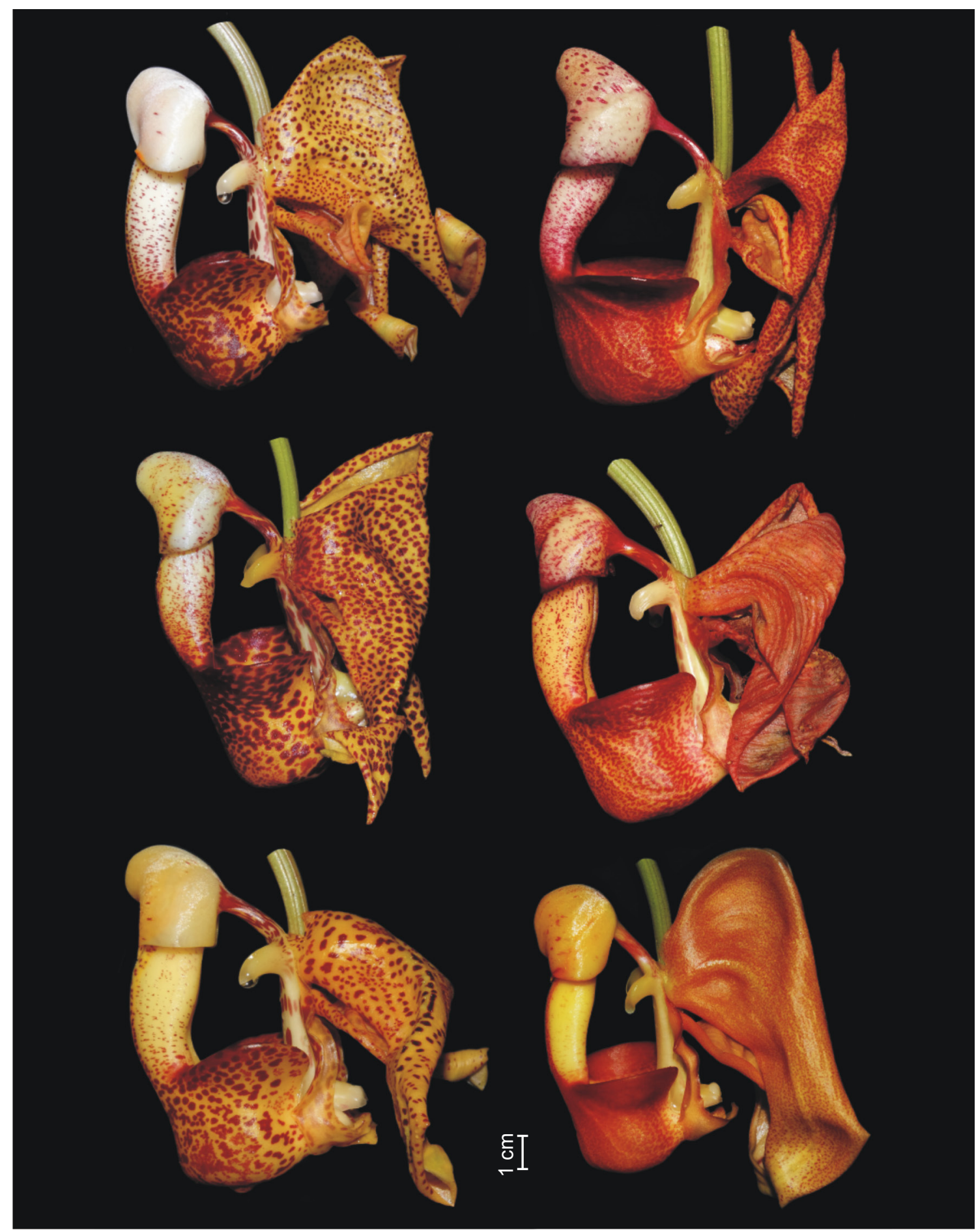

Figura 6 - Coryanthes speciosa (Hook.) Hook. - variação morfológica e de coloração nas flores de uma mesma população. Figure 6 - Coryanthes speciosa (Hook.) Hook. - variation of flower's color and morphology in the same population. 
das matas ripárias do Rio Juruena, está depositado no Herbário R ( $\left.n^{\circ} 3030\right)$ e possui suas flores com o perianto parcialmente destruído (Fig. 5a), contudo em sua obra Hoehne (1910) ilustrou o espécime (Fig. 5b) tornando possível a sua identificação. Uma vez que $C$. speciosa não era coletada há 87 anos no estado do Mato Grosso, trata-se da redescoberta da espécie no estado.

O material oriundo do rio Teles Pires foi encontrado como epífita sobre formigueiros, a uma altura de sete a oito metros do solo em árvores do estrato médio. Encontrada florida em maio, setembro, outubro e novembro, com flores durando cerca de três a cinco dias. No fruto as pétalas e sépalas se decompõem, permanecendo o labelo que seca e adquire coloração castanha.

Apesar de não ser a espécie típica do gênero, esta foi a primeira a ser descrita por Hooker (1827) no gênero Gongora. É relativamente similar a $C$. maculata, de modo que muitas variedades de $C$. maculata são tratadas atualmente como sinônimos de C. speciosa. Entre as espécies de Mato Grosso, pode ser diferenciada pelo mesoquílo desprovido de calos lamelares transversos e pela faixa dorsal longitudinal velutina. Apresenta considerável variação na tonalidade das flores, bem como na densidade e tamanho das máculas (Fig. 6). A forma do unguículo do hipoquílo também varia de arredondado a cônico, com reentrâncias maiores ou menores em seu dorso (Fig. 6).

Coryanthes wenzeliana G.Gerlach \& J.B.F.Silva, Orchideen J. 17: 34. 2010. Tipo: BRASIL, MATO GROSSO: Sinop (ca. $400 \mathrm{~km}$ noroeste de Cuiabá), cultivado no Jardim Botânico de Munique (München-Nynphenburg) sob número 08/2052, fl., XII.2009, sine col. [holótipo: SP 426587 (foto!); isótipo $\mathrm{M}$ (foto!)].

Fig. 7

Raízes 0,1-0,2 cm diâm. Rizoma 3-4 mm diâm., ca. 1 cm compr. entre pseudobulbos. Pseudobulbos 5,5-7,1 $\times 1-1,9 \mathrm{~cm}$, lanceoloides a ovoides. Folhas $2-3,20,1-31 \times 2,6-4,8$ $\mathrm{cm}$, elípticas a oblanceoladas. Inflorescência ascendente a patente, 1-2-flora; pedúnculo 15-20,1 × 0,3-0,4 cm, verde claro; brácteas do pedúnculo $1,5-1,7 \times 1-1,2 \mathrm{~cm}$, oblongas; raque 2,5-3,4 × 0,2-0,3 cm, cilíndrica, verde; brácteas florais ca. 2,1 × 1,2 cm, ovadas. Flor com ovário + pedicelo 7,5-10 × ca. 0,4 cm, verde; sépala dorsal ca. 2,3 × 2,7 cm, amarelo pálido a esverdeado; sépalas laterais $7,4-8 \times$ ca. $3 \mathrm{~cm}$, amarelo pálido a esverdeado, com pintas castanho-rosadas claras; pétalas ca. $3,7 \times 0,8 \mathrm{~cm}$, alvo-esverdeadas, com pintas castanho-rosadas claras; labelo subdividido; hipoquílo 2,6-2,9 × 1-1,3 cm, patente; unguículo laminar, lamelar-bicaloso, apicalmente piloso, verde claro, rajado de vináceo, tricomas alvos; mesoquílo 1,3-2,2 × 0,6-1,5 cm, glabro, com calos lamelares transversos, maior na base, verde, rajado de vináceo; calos lamelares 1-6 × 1-3 mm, inteiros a bilobados, verdes, rajados de vináceo; calo basal ausente; epiquílo 3,1-3,5 × 4,4-5,4 cm, alvo-esverdeado, com pintas castanho-rosadas claras; calo $0,1 \times 0,2 \mathrm{~cm}$; apículos laterais $0,5 \times 0,3$ $\mathrm{cm}$, agudos; apículo central 1-1,2 cm, espatulado. Coluna ca. $2 \times 0,5 \mathrm{~cm}$, verde claro; glândulas $8 \times$ $3 \mathrm{~mm}$, elípticas, alvo-esverdeadas; calos laterais ca. $5 \times 2 \mathrm{~mm}$, arredondados, translúcidos; alas ca. $2 \times 2 \mathrm{~mm}$, agudas, translúcidas; antera ca. $4 \times 2$ $\mathrm{mm}$, globosa, alva; polínias ca. $2 \times 1 \mathrm{~mm}$; estipe ca. $2 \times 1 \mathrm{~mm}$, deltoide; viscídio ca. $1,5 \times 1 \mathrm{~mm}$, arredondado. Fruto após deiscência $8 \times 2,5 \mathrm{~cm}$, elíptico, castanho. Sementes não vistas.

Material examinado: Itaúba, Resgate de Flora da UHE Colíder, Lote C de supressão. 7.IX.2014, fl., M.E.Engels \& R.Barreto 3319 (MBM); 27.IX.2014, fl., M.E.Engels \& R. Barreto 3321 (MBM, TANG, RB); 8.X.2014, fl., M.E.Engels \& R.Barreto 3320 (MBM, TANG, CNMT); 13.X.2014, fl., M.E.Engels \& R.Barreto 3318 (MBM); Resgate de Flora da UHE Colíder, Lote D de supressão, 8 XII. 2014, fl., M.E.Engels 3322 (MBM, TANG).

Coryanthes wenzeliana é endêmica do Brasil, no estado de Mato Grosso (Gerlach 2010; Govaerts 2015). Até o momento era conhecida somente pelo material tipo, oriundo do município de Sinop.

Espécie que ocorre como epífita sobre formigueiro em árvores do estrato médio da floresta, a altura de sete a oito metros do solo, nas matas ao longo do rio Teles Pires. Encontrada florida em setembro, outubro e dezembro, com flores durando ca. de quatro dias. A coloração varia do esverdeado na antese para amarelado na senescência. No fruto as pétalas e sépalas se decompõem, permanecendo o labelo que seca e adquire coloração castanha.

Descrita recentemente, essa espécie assemelha-se a C. pegiae G.A. Romero da Venezuela, da qual se diferencia especialmente pelo mesoquílo com três séries de lamelas ( $v s$. duas séries) e coloração verde clara (vs. roxo nigrescente). Pode ser reconhecida entre as espécies do estado pela inflorescência ascendente a patente, que não ultrapassa o comprimento das folhas; pelo hipoquílo do labelo com um par de calos lamelares apicalmente pilosos (sendo este 


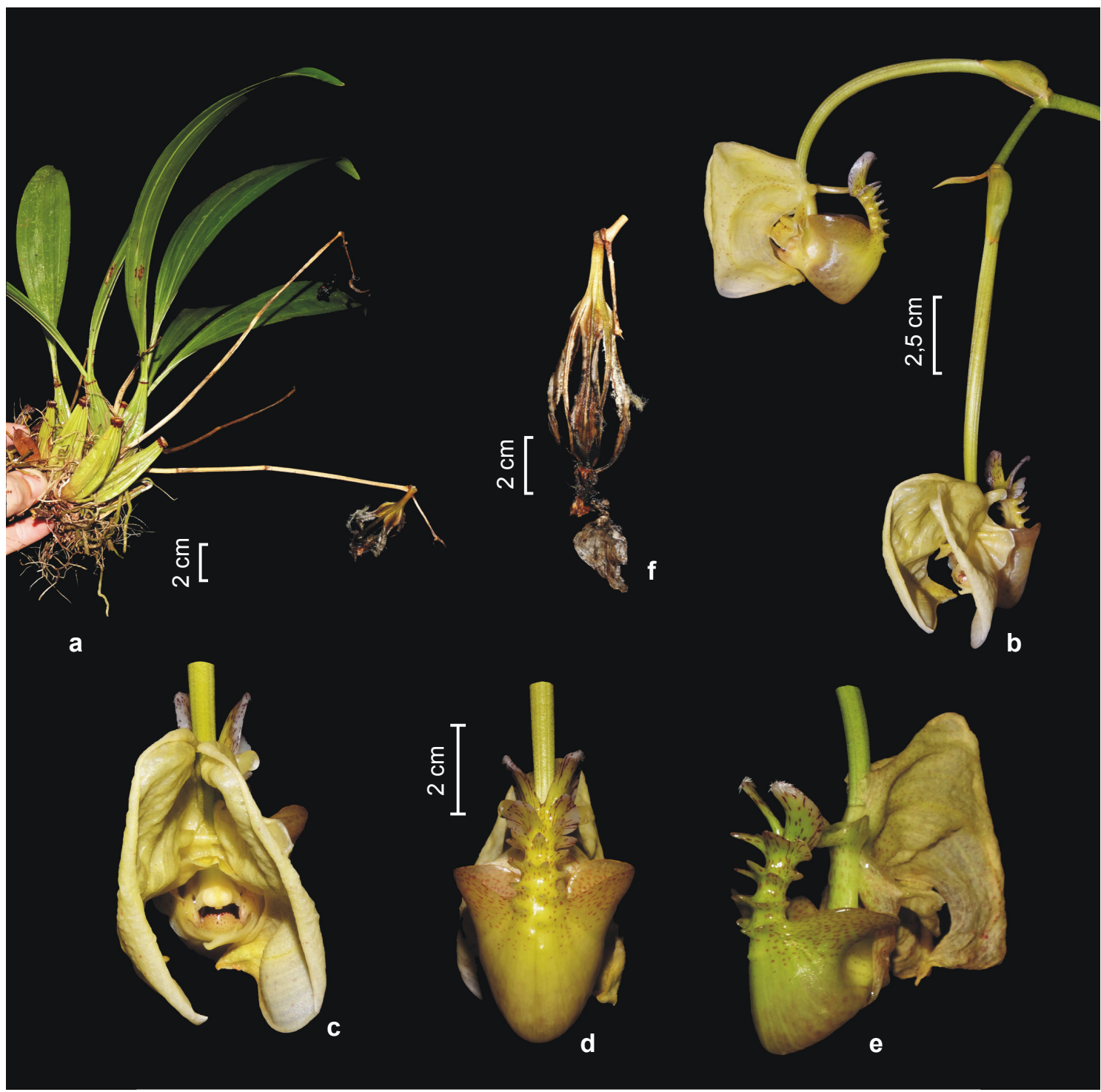

Figura 7 - Coryanthes wenzeliana G.Gerlach \& J.B.F.Silva - a. hábito; b. detalhe da inflorescência; c-e. flor; c. vista frontal; d. vista dorsal; e. vista dorsolateral; f. fruto pós deiscência.

Figure 7 - Coryanthes wenzeliana G.Gerlach \& J.B.F.Silva - a. habit; b. detail of the inflorescence; c-e. flower; c. frontal view; d. dorsal view; e. dorso-lateral view; f. post dehiscence fruit.

não unguiculado, ao contrário da maioria das demais espécies do gênero que é unguiculado); e pelo mesoquílo densamente caloso-lamelado.

\section{Agradecimentos}

À Companhia Paranaense de Energia (COPEL), por permitir e incentivar a publicação dos dados aqui contidos. Ao Consórcio CIA Ambiental e seus colaboradores. A Fábio de Barros, Alice Gerlach e Tiago Vieira, o auxílio com bibliografias, e a Marlon Almeida, a ajuda com o acervo R. Aos curadores e técnicos de herbário, o auxílio e disposição das coleções.

\section{Referências}

Barros, F. 2001. Uma nova espécie de Coryanthes (Orchidaceae) da Amazônia brasileira. Hoehnea 28: 279-283.

BFG. 2015. Growing knowledged: an overview of seed plants diversity in Brazil. Rodriguésia 66: 1085-1113. 
Cogniaux, C.A. 1898. Coryanthes. In: Martius, C.F.P. Von, Eichler, A.W. \& Urban, I. Flora brasiliensis. Typographia Regia C. Wolf et fil., Monachii et Lipsiae. Vol 3, pars 5, pp. 508-516.

Dubs, B. 1998. Prodromus Florae Matogrossensis: Part I. Checklist of Angiosperms, Parte II: Typus from Mato Grosso. Betrona-Verlag, Küsnacht. 444p.

Fidalgo, O. \& Bononi, V.L.R. 1989. Técnicas de coleta, preservação e herborização de material botânico. Reimpressão. Instituto de Botânica, São Paulo. 62p.

Gerlach, G. 2009. Coryanthes. In: Pridgeon, A.M.; Cribb, P.J.; Chase, M.W. \& Rasmussen, F.N. Genera Orchidacearum. Vol. 5. Oxford University Press, New York. Pp. 407-411.

Gerlach, G. \& Whitten, W.M. 2009. Stanhopeinae. In: Pridgeon, A.M.; Cribb, P.J.; Chase, M.W. \& Rasmussen, F.N. Genera Orchidacearum. Vol. 5. Oxford University Press, New York. Pp. 394-399.

Gerlach, G. 2010. Coryanthes mystax und Coryanthes wenzeliana: zwei neue Coryanthes-Arten aus dem amazonischen Brasilien. Orchideen Journal 17: 28-36.

Gonçalves, E.G. \& Lorenzi, H. 2011. Morfologia vegetal: organografia e dicionário ilustrado de morfologia das plantas vasculares. $2^{\mathrm{a}}$ ed. Instituto Plantarum de Estudos da Flora, Nova Odessa. 512p.

Govaerts, R. 2015. World checklist of Orchidaceae. Facilitated by the Royal Botanic Gardens, Kew. Disponível em $<$ http://apps.kew.org/wcsp/qsearch. do $>$. Acesso em 3 agosto 2015.

Hoehne, F.C. 1910. História natural: Botânica. Parte I: Bromeliaceas, Pontederiaceas, Liliaceas, Amaryllidaceas, Iridaceas, Orchidaceas, Aristolochiaceas, Droseraceas e Passifloraceas. Comissão de Linhas Telegraphicas e Estratégicas de Mato Grosso ao Amazonas, Rio de Janeiro. 71p.

Hoehne, F.C. 1942. Orchidaceas. In: Hoehne, F.C. Flora Brasílica. Fascículo 5. Vol. 12. Parte VI. Gráficas F. Lanzara, São Paulo. 218p.
Hooker, W.J. 1827. Gongora speciosa. Botanical Magazine 54: t. 2755.

Hooker, W.J. 1831. Coryanthes maculata: spotted-lipped Coryanthes. Botanical Magazine 58: t. 3102.

Hooker, W.J. 1831. Gongora macrantha. Botanical Miscellany 2: 151, t.80.

Koch, A.K. \& Silva, C.A. 2012. Orquídeas nativas de Mato Grosso. Carlini \& Caniato Editora, Cuiabá. 112p.

Marçal, S. \& Chiron, G.R. 2013. Orchidaceae: trois nouveaux táxons de Bahia (Brésil). Richardiana 14: 3-18.

Pabst, G.F.J. \& Dungs, F. 1975. Orchidaceae Brasilienses I. Brucke-Verlag Kurt Schmersow, Hildesheim. 408p.

Pabst, G.F.J. \& Dungs, F. 1977. Orchidaceae Brasilienses II. Brucke-Verlag Kurt Schmersow, Hildesheim. $418 \mathrm{p}$.

Petini-Benelli, A. 2012. Orquídeas de Mato Grosso Genus Catasetum L.C. Rich ex Kunth. PoD editora, Rio de Janeiro. 130p.

Sasaki, D.; Zappi, D.; Milliken, W.; Henicka, G.S. \& Piva, J.H. 2010. Vegetação e plantas do Cristalino - um manual. Gráfica e editora Viena, Santa Cruz do Rio Pardo. 128p.

Schlechter, R. 1916. Die gattung Coryanthes Hook. Orchis 10: $67-82$.

Thiers, B. [continuously updated]. Index Herbariorum. Part I: The herbaria of the world. New York Botanical Garden. Disponível em <http://sweetgum.nybg.org/ $\mathrm{ih} />$. Acesso em 3 agosto 2015.

Whitten, W.M.; Williams, N.H. \& Chase, M.W. 2000. Subtribal and generic relationships of Maxillarieae (Orchidaceae) with emphasis on Stanhopeinae: combined molecular evidence. American Journal of Botany 87: 1842-1856.

Zappi, D.C.; Sasaki, D.; Milliken, W.; Iva, J.; Henicka, G.S.; Biggs, N. \& Frisby, S. 2011. Plantas vasculares da região do parquet estadual do Cristalino, norte de Mato Grosso, Brasil. Acta Amazonica 41: 29-38. 